\title{
Intradialytic Hypertension and Associated Factors among Chronic Haemodialysed Patients in Sub-Saharan Africa: An Example from Cameroon
}

\author{
Halle Marie Patrice ${ }^{*}$, Bana Eric Loïc ${ }^{1}$, Fouda Hermine², Nda Mefo'o Jean Pierre1, \\ Tewafeu Denis ${ }^{3}$, Kaze Folefack François ${ }^{2}$, Ashuntantang Enow Gloria ${ }^{2}$ \\ ${ }^{1}$ Faculty of Medicine and Pharmaceutical Sciences, University of Douala, Cameroon \\ ${ }^{2}$ Faculty of Medicine and Biomedical Sciences, University of Yaoundé I, Yaounde, Cameroon \\ ${ }^{3}$ Faculty of Health Sciences, University of Buea, Buea, Cameroon \\ Email: ^patricehalle@yahoo.fr, ericloicbana@yahoo.fr, mendjouf@yahoo.fr,drnda41@yahoo.fr, dengeorgt@yahoo.com, \\ f_kaze@yahoo.fr, maglo09@hotmail.com
}

How to cite this paper: Patrice, H.M., Loïc, B.E., Hermine, F., Pierre, N.M.J., Denis, T., François, K.F. and Gloria, A.E. (2018) Intradialytic Hypertension and Associated Factors among Chronic Haemodialysed Patients in Sub-Saharan Africa: An Example from Cameroon. Open Journal of Nephrology, 8, 105-116.

https://doi.org/10.4236/ojneph.2018.84012

Received: October 7, 2018

Accepted: December 1, 2018

Published: December 4, 2018

Copyright ( $\odot 2018$ by authors and Scientific Research Publishing Inc. This work is licensed under the Creative Commons Attribution International License (CC BY 4.0).

http://creativecommons.org/licenses/by/4.0/ (c) (i) Open Access

\begin{abstract}
Background: Hemodialysis (HD) is a therapy during which complications such as intradialytic hypertension (IDH) are frequent. We aimed to determine the incidence of IDH and associated factors amongst patients on maintenance hemodialysis in Cameroon. Method: It was a prospective cohort study including end stage kidney disease patients on HD. Data collected were: socio-demographic, comorbidities, current medication, weight, heart rate ultrafiltration rate (UF), albuminemia and electrocardiogram. The first blood pressure (BP) measurement was obtained at the beginning of the session and the last at the end. IDH was defined as an increase in systolic BP $\geq 10 \mathrm{mmHg}$ between the first and the last measurement. Logistic regression was used to look for associated factors, $\mathrm{p}$-value $<0.05$ was considered significant. Results: Mean age was $49.06 \pm 13.97$ years with $64.2 \%$ males. Mean number of dialysis session was $11.26 \pm 2.49$. Incidence of IDH was $48.36 \%$. The median number of IDH episodes was 5 (Range 0 - 12). Factors increasing the risk were hypertension ( $\mathrm{p}=0.003)$, number of antihypertensive drugs $\geq 2(\mathrm{p}<0.001)$, blood transfusion during the session $(\mathrm{p}<0.001)$, male gender $(\mathrm{p}=0.038)$ and $\mathrm{a}$ monthly income $<35000$ XAF ( $p=0.033$ ). Factors lowering the risk were age $\geq 50$ years $(\mathrm{p}=0.012)$, longer duration on dialysis $(\mathrm{p}<0.001)$, dry weight $\geq$ $67 \mathrm{~kg}(\mathrm{p}<0.001), \mathrm{UF} \geq 800 \mathrm{ml} / \mathrm{h}(\mathrm{p}<0.001)$ and a $\mathrm{BP} \geq 140 / 90 \mathrm{mmHg}$ at the beginning of the session $(\mathrm{p}<0.001)$. Conclusion: IDH is frequent amongst patients on maintenance hemodialysis in our setting, with various patients related factors associated.
\end{abstract}




\section{Keywords}

Hemodialysis, Intradialytic Hypertension, Incidence, Associated Factors, Cameroon

\section{Introduction}

Hemodialysis (HD) is a life-sustaining treatment for patients with end stage kidney disease (ESKD) and hypertension (HTN) is a common problem amongst these patients [1] [2]. During HD, blood pressure (BP) changes occur frequently and large variability in $\mathrm{BP}$ is a risk factor for increased mortality in these patients [3]. Normally during the dialysis session, BP reduction occurs in most patients, but some patients will in the contrary have a significant increase in BP. This phenomenon called intradialytic hypertension (IDH) is a well-recognized problem amongst patients on HD. No standard definition of IDH exists, but the one with clinical relevance used by many authors is an increase in systolic blood pressure (SBP) of $10 \mathrm{mmHg}$ or more from pre to post-HD blood pressure values [4].

Reported prevalence of IDH ranged from $13.2 \%$ to $33.9 \%$ (Figure 1) and the phenomenon was associated with adverse outcome [5]-[10]. Mortality amongst patients with ESKD is known to be high mainly from cardiovascular origin [2] [11] and studies have shown that IDH is a risk factor for cardiovascular events and death [2] [7] [12]. In the study of Inrig et al., two-year mortality was increased amongst incident patients with IDH and the odd of death and hospitalization at 6 months was increased by $20 \%$ in prevalent patients [7] [12]. The cause of IDH is not well established, but volume overload is suggested to be a key factor for its development [13] [14]. Others factors playing a role in his pathogenesis are sympathetic nervous system over-activity [15] [16], activation of the

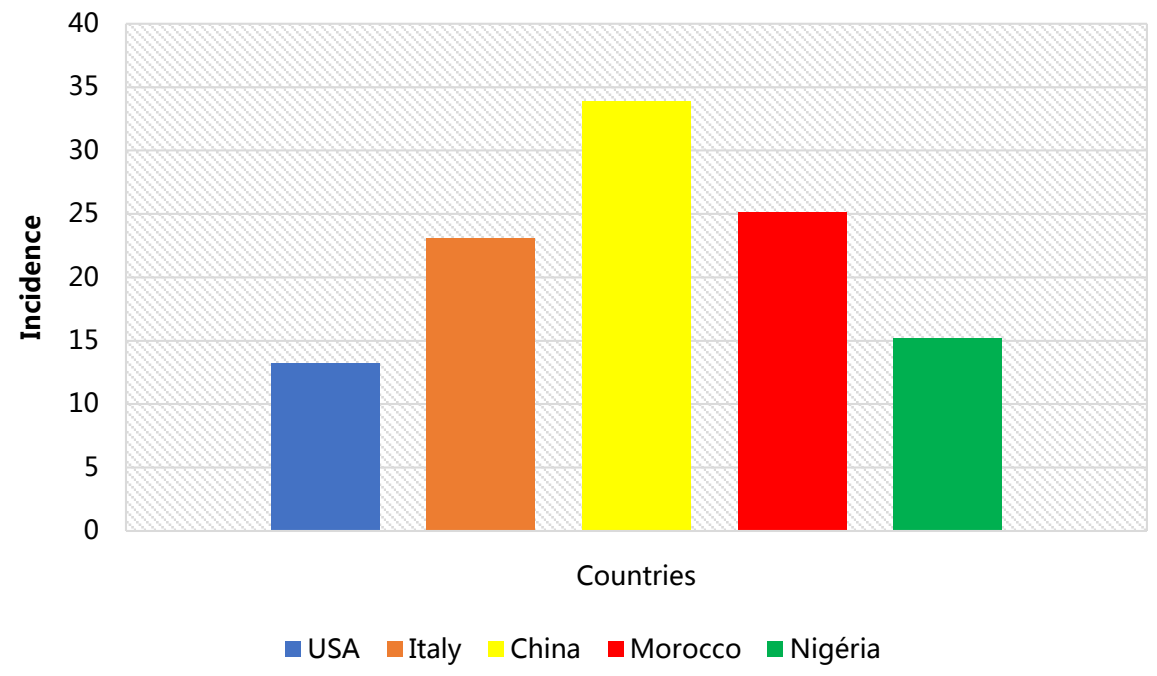

Figure 1. Incidence of IDH by country. 
renin-angiotensin-aldosterone system (RAAS), endothelial cell dysfunction [17] [18], changes in sodium, potassium and calcium levels during dialysis [19] [20] [21], removal of antihypertensive medications by the dialysis procedure such as angiotensin converting enzyme (ACE) inhibitors and some beta-blockers [22], and use of erythropoietin stimulating agents (ESA) [23] [24]. Also older age, low dry weight, history of HTN, use of a great number of antihypertensive medications, low serum creatinine and low serum albumin were reported to be associated to IDH [12] [25].

In sub-Saharan Africa in general and in Cameroon in particular, hypertension, a major cause of CKD is highly prevalent in patients with ESKD on HD [26] [27] [28] [29]. HD has been expanded in Cameroon in the last decade with almost 1200 patients on treatment at the end of the year 2016. A study by Kaze et al. reported that hypertensive crises defined as any symptomatic increase in SBP of at least $30 \mathrm{mmHg}$ from the value at the beginning of the dialysis session was the $3^{\text {th }}$ leading acute complication amongst patients on HD [27]. Despite the proven adverse outcomes of IDH, data on that phenomenon are inexistent in Cameroon. Therefore, the aim of the present study was to determine the burden of IDH and associated factors amongst patients on maintenance HD in Cameroon.

\section{Methods}

\subsection{Study Setting}

We conducted a prospective cohort study in the HD unit of the Douala general hospital (DGH) in Cameroon, from January 2016 to March 2016. DGH is tertiary public institution which serves as referral hospital for patients with kidney diseases for the littoral region of the country [30]. At the time of the study the center was equipped with 20 Fresenius ${ }^{\circledR} 4008$ S generators (Fresenius Medical Care, Hamburg, Germany), and used synthetic polysulfone dialysis membrane, bicarbonate and a dialysate with $140 \mathrm{Meq} / \mathrm{l}$ of sodium. The center operates from Monday to Saturday with 4 shift dialysis per day from 5:00am to midnight. A total of 187 chronic patients were registered, they received 2 dialysis sessions of 4 hours duration each per week. The unit was operating with 2 nephrologists, 1 general practitioner and 12 state registered nurses. Nurses were working in groups according to time schedules: the daytime team (from 6:00 am to 5:00 pm) and the nighttime team (from 5:00 pm to 12:00 pm). Dry weight is assessed by the nephrologists. This study received administrative authorization from the DGH and was approved by the ethic comity of the Douala University, Cameroon. All consenting patients who were following their HD treatment at the DGH where included, while we excluded patients with ESKD who performed temporarily $\mathrm{HD}$ session at DGH and those on whom blood pressure measurement was not possible in the arm.

\subsection{Data Collection}

During the study period, socio demographic, clinical and biological data were 
recorded from all consenting ESKD patients and medical records. This included: age, gender, monthly income, comorbidity (HTN, diabetes, left ventricular hypertrophy (LVH), gout, polycystic kidney disease (PKD), Human immunodeficiency virus (HIV), baseline nephropathy, duration on dialysis, number of sessions per week, current medication such as antihypertensive drugs, erythropoietin stimulating agent (ESA) and calcium containing drugs. We monitored dialysis sessions of patients, the follow-up was performed from the $18^{\text {th }}$ of January 2016 to the $31^{\text {st }}$ of March 2016. Data collected on dialysis days were: BP and heart rate during the session, interdialytic interval, presence of edema, dry weight, and weight before and after the session, UF rate, consumption of antihypertensive drugs, blood transfusion and the volume of blood transfused during the session.

At each session BP was measured on the arm without vascular access using an automatic manometer supplied with the dialysis generators (Fresenius ${ }^{\circledR} 4008 \mathrm{~S}$ ). The first measurement was performed five minutes before the beginning of the session, after a resting period of at least fifteen minutes and before the needle insertion. The measurements were then made every hour and the last one at the end of the session before restitution. Heart rate was recorded the same way. Weight measurement was done before and after the dialysis session, the patient dressed the same way with a "SOENLHE 7708" electronic scale.

For each participant $3 \mathrm{ml}$ of blood was collected at the beginning of the study for albumin dosage in the biochemistry laboratory of the DGH using an automat Cobas 311. An electrocardiogram was performed after the first dialysis session with a CARDIART $6108 \mathrm{~T}$ to search for left ventricular hypertrophy (LVH) using Sokolow index (S wave depth in V1 + tallest R wave height in V5 or V6 > 35 $\mathrm{mm})$ [31].

\subsection{Definitions}

IDH was defined as an increase of at least $10 \mathrm{mmHg}$ in SBP between the beginning and the end of the dialysis session.

Interdialytic interval was the number of days between two successive dialysis sessions.

Interdialytic weight gain was the difference between patient's weight at the beginning of the session and the weight at the end of the previous session. Incidence of IDH was expressed by multiplying the number of sessions with IDH by 100 over the total number of sessions followed.

Etiology of CKD was mainly done clinically in the absence of renal histology.

A treatment was considered regular when a patient follows it as prescribed by the treating physicians.

\subsection{Statistical Analysis}

Data were analyzed using STATA 12.0. Quantitative variables were expressed as average with the standard deviation or median and compared with the Wilcoxon test. Categorical variables were expressed in numbers and percentages and then 
compared using the Fischer test. The search for associated factors was done using univariate logistic regression model. Data with a p-value equal or less than $20 \%$ were then included in a bivariate analysis by adjusting the different input data. A p value $<0.05 \%$ was considered statistically significant.

\section{Results}

\subsection{General Characteristic of the Study Participants}

A total of 176 patients were followed during 1981 dialysis sessions, with an average of $11.26 \pm 2.49$ sessions per patient. The mean age of participants was $49.06 \pm 13.9$ years, $64.2 \%(113 / 176)$ were male and $50.5 \%$ of patients $(89 / 176)$ had a monthly income $<35,000$ XAF. The prevalence of HTN was $89.7 \%$ (158/176) with $137 / 158$ on antihypertensive drugs amongst which only $46.7 \%$ (64/137) followed regular treatment. Diabetes was more common in males $(\mathrm{p}=$ $0.001)$ while female were more HIV positive $(\mathrm{p}=0.014)$. The median duration on HD was 26.5 months (range: 1 - 396). Clinical characteristics are summarized in Table 1.

Table 1. Sociodemographic and clinical characteristics of the study population.

\begin{tabular}{|c|c|c|c|c|}
\hline Variable & Overall & Men & Women & p-value \\
\hline Number & 176 & 113 & 63 & - \\
\hline Mean age \pm SD & $49.06 \pm 13.97$ & $50.69 \pm 13.89$ & $46.15 \pm 13.73$ & 0.054 \\
\hline Monthly income < 35000 n (\%) & $89(50.57)$ & $38(33.63)$ & $51(80.95)$ & $<0.001$ \\
\hline Arterio-venous fistula n (\%) & $165(93.75)$ & $103(91.15)$ & $62(98.41)$ & 0.100 \\
\hline Mean duration on dialysis (months) & 26.5 & 26 & 27 & 1.000 \\
\hline Two weekly sessions n \% & $171(97.16)$ & $110(97.35)$ & $61(96.83)$ & 1.000 \\
\hline \multicolumn{5}{|l|}{ Comorbidities } \\
\hline Hypertensionn (\%) & $158(89.77)$ & $103(91.15)$ & $55(87.30)$ & 0.444 \\
\hline HTN mean duration \pm SD (years) & $9.09 \pm 6.62$ & $8.91 \pm 6.64$ & $9.44 \pm 6.62$ & 0.624 \\
\hline HTN treatment $\mathrm{n}(\%)$ & $137(86.71 \%)$ & - & - & - \\
\hline HTN with regular treatment $\mathrm{n}(\%)$ & $64(46.72 \%)$ & - & - & - \\
\hline Diabetes n (\%) & $34(19.32)$ & $30(26.55)$ & $4(6.35)$ & 0.001 \\
\hline Left ventricular hypertrophy n (\%) & $96(54.55)$ & $57(50.44)$ & $39(61.90)$ & 0.158 \\
\hline HIV n (\%) & $13(7.39)$ & $4(3.54)$ & $9(14.29)$ & 0.014 \\
\hline Gout n (\%) & $10(5.68)$ & $9(7.96)$ & $1(1.59)$ & 0.098 \\
\hline Use of ESA n (\%) & $42(23.86)$ & $29(25.66)$ & $13(20.63)$ & 0.580 \\
\hline Use of calcium n (\%) & $131(74.43)$ & $86(76.11)$ & $45(71.43)$ & 0.589 \\
\hline \multicolumn{5}{|l|}{ Background nephropathy n (\%) } \\
\hline Nephroangiosclerosis & $29(16.48)$ & $23(20.35)$ & $6(9.52)$ & 0.089 \\
\hline Diabetes Nephropathy & $25(14.20)$ & $21(18.58)$ & $4(6.35)$ & 0.026 \\
\hline HIV & $10(5.68)$ & $4(3.54)$ & $6(9.52)$ & 0.170 \\
\hline Chronic glomerulonephritis & $43(24.43)$ & $28(24.78)$ & $15(23.81)$ & 1.000 \\
\hline Chronic interstitial nephritis & $9(5.11)$ & $5(4.42)$ & $4(6.35)$ & 0.723 \\
\hline Polycystic kidney disease & $2(1.14)$ & $0(0.00)$ & $2(3.17)$ & 0.127 \\
\hline Unknown & $58(32.95)$ & $32(28.32)$ & $26(41.27)$ & 0.095 \\
\hline
\end{tabular}

SD: standard deviation, HTN: hypertension, HIV: human immunodeficiency virus. 


\subsection{Incidence of IDH and Associated Factors}

The incidence of IDH was $48.3 \%$ (Figure 2) and was higher in women compared to men ( $p=0.01)$. A total of $71.18 \%(1410 / 1981)$ HD sessions followed were initiated with $\mathrm{BP} \geq 140 / 90 \mathrm{mmHg}$. The characteristics of the sessions are summarized in Table 2. During the study, 93.7\% (165/176) patients had at least one episode of IDH with a median of 5 episodes per patient (range 0 - 12). In bivariate analysis, factors that increase the risk of IDH were HTN $(\mathrm{p}=0.004$; RR $=1.3)$, male gender $(\mathrm{p}=0.038 ; \mathrm{RR}=1.14)$, monthly income $<35,000 \mathrm{XAF}(\mathrm{p}=0.028$; $R R=1.13)$, blood transfusion during the session $(\mathrm{p}<0.001 ; \mathrm{RR}=1.57)$ and use of $\geq 2$ antihypertensive drugs $(\mathrm{p}<0.001 ; \mathrm{RR}=1.27)$. Factors associated with lower risk were age $\geq 50$ years ( $\mathrm{p}=0.012$; $R R=0.86$ ), longer duration on dialysis $\geq 30$ months $(\mathrm{p}<0.001 ; \mathrm{RR}=0.8)$, dry weight $\geq 67 \mathrm{~kg}(\mathrm{p}<0.001 ; \mathrm{RR}=0.77)$, UF rate $\geq 800 \mathrm{ml} / \mathrm{h}(\mathrm{p}<0.001 ; \mathrm{RR}=0.71)$ and $\mathrm{BP}$ at the beginning of the session $\geq$ $140 / 90 \mathrm{mmHg}(\mathrm{p}<0.001 ; \mathrm{RR}=0.56)($ Table 3$)$.

\section{Incidence of intradialytic hypertension}

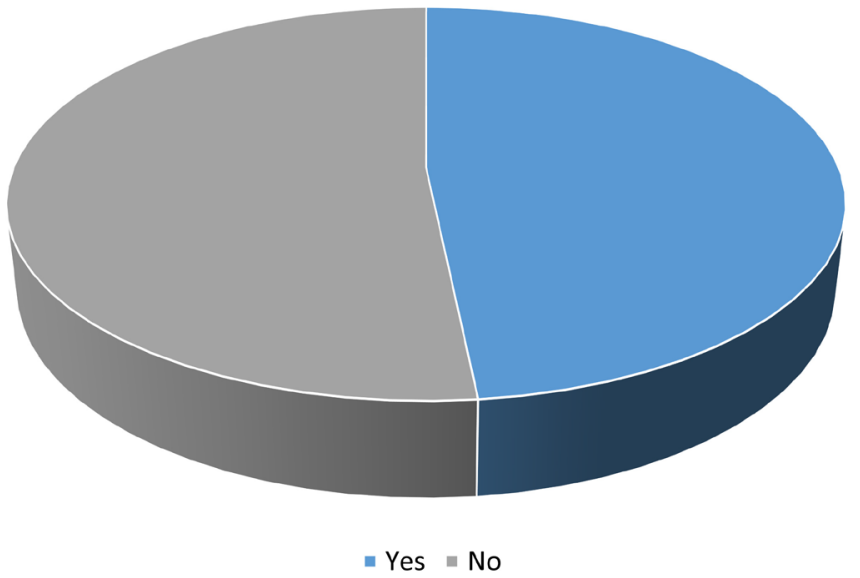

Figure 2. Incidence of IDH.

Table 2. General characteristics of dialysis sessions.

\begin{tabular}{ccccc}
\hline Variable & Overall & Men & Women & p-value \\
\hline Number & 1981 & 1261 & 720 & - \\
Mean \pm SD & $11.26 \pm 2.49$ & $11.16 \pm 2.68$ & $11.43 \pm 2.13$ & 0.655 \\
Mean SBP at the beginning \pm SD & $154.25 \pm 23.60$ & $155.10 \pm 24.05$ & $152.74 \pm 22.87$ & 0.37 \\
Mean SBP at the end \pm SD & $162.68 \pm 24.91$ & $162.08 \pm 22.03$ & $163.75 \pm 29.54$ & 0.70 \\
Mean DBP at the beginning \pm SD & $81.69 \pm 15.29$ & $81.17 \pm 16.61$ & $82.61 \pm 12.64$ & 0.55 \\
Mean DBP at the end \pm SD & $86.60 \pm 15.12$ & $86.19 \pm 15.58$ & $87.32 \pm 14.35$ & 0.65 \\
BP at beginning $\geq 140 / 90$ mmHg n (\%) & $1410(71.18)$ & $949(75.26)$ & $461(64.03)$ & $<0.001$ \\
$\Delta$ SBP $>$ 10 mmHg at any moment n (\%) & $1297(65.47)$ & $802(63.60)$ & $495(68.75)$ & 0.021 \\
Edema n $(\%)$ & $252(12.72)$ & $177(14.04)$ & $75(10.42)$ & 0.021 \\
Blood transfusion n (\%) & $88(4.44)$ & $44(3.49)$ & $44(6.11)$ & 0.009 \\
\hline
\end{tabular}

DS: standard deviation; SBP: systolic blood pressure; DBP: diastolic blood pressure; $\triangle$ SBP: postdialysis SBP minus predialysis SBP. 
Table 3. Associated factors to intradialytic hypertension.

\begin{tabular}{cccc}
\hline Variable & RR & CI 95\% & p-value \\
\hline Male gender & 1.14 & $1.01-1.26$ & 0.038 \\
Age $\geq 50$ years & 0.86 & $0.76-0.97$ & 0.012 \\
Monthly income $<35,000$ XAF & 1.13 & $1.01-1.25$ & 0.028 \\
Hypertension & 1.30 & $1.10-1.48$ & 0.004 \\
Left ventricular hypertrophy & 1.05 & $0.94-1.17$ & 0.358 \\
Use of ESA & 1.01 & $0.88-1.13$ & 0.926 \\
Guration on dialysis $\geq 30 \mathrm{months}$ & 0.80 & $0.71-0.90$ & $<0.001$ \\
Gout & 0.79 & $0.59-1.01$ & 0.058 \\
Dry weight $\geq 67 \mathrm{~kg}$ & 0.77 & $0.67-0.88$ & $<0.001$ \\
Ultrafiltration rate $\geq 800 \mathrm{~mL} / \mathrm{h}$ & 0.71 & $0.60-0.81$ & $<0.001$ \\
Heart rate $\geq 75 \mathrm{bpm}$ & 1.08 & $0.98-1.18$ & 0.105 \\
BP at the beginning $\geq 140 / 90 \mathrm{mmHg}$ & 0.56 & $0.46-0.66$ & $<0.001$ \\
Blood transfusion & 1.57 & $1.33-1.75$ & $<0.001$ \\
Number of antihypertensive drugs $\geq 2$ & 1.27 & $1.15-1.38$ & $<0.001$ \\
\hline
\end{tabular}

BP: blood pressure. ESA: erythropoietin stimulating agents.

\section{Discussion}

The aim of this study was to determine the incidence and factors associated to IDH amongst ESKD patients in Cameroon. We found that our patients were relatively young adults, mainly men and hypertension was the main comorbidity affecting 9 of 10 patients. IDH was frequent with an incidence of $48.3 \%$. Factors associated with increased risk of IDH were HTN, male gender, low monthly income, blood transfusion during the session and use of 2 or more antihypertensive drugs. Factors associated with lower risk were age $\geq 50$ years, longer duration on dialysis, dry weight $\geq 67 \mathrm{~kg}$, high UF rate and high $\mathrm{BP}$ at the start of dialysis session.

Elevation of $\mathrm{BP}$ during $\mathrm{HD}$ is a frequent but an ignored phenomenon amongst patients on HD. Clinicians focus more on intradialytic hypotension and its complications because it is more symptomatic, despite the proven adverse outcome of IDH namely the increased risk of hospitalization and death [12]. This study revealed that IDH is very frequent amongst patients on HD in Cameroon with an incidence of $48.3 \%$. The reported prevalence of IDH varies depending on the number of HD treatments in which BP measurements occur and the definitions used. Our result is one of the highest compared to the reported incidence in the literature [5]-[10]. Considering IDH as an increase at least $10 \mathrm{mmHg}$ from pre to post-HD mean SBP from all sessions, Inrig et al. reported a prevalence of $13.2 \%$ in a retrospective study where prevalent HD patients were assessed over 4 HD sessions, and a prevalence of $12.2 \%$ was found in incident one when BP measurements were assessed over 2 weeks [7] [12]. Amira et al. in Nigeria re- 
ported a prevalence of $15.2 \%$, defining IDH as an increase of BP during the second or third hour after significant ultrafiltration [5], but in that study the level of BP to define IDH was not clear also the definition of significant UF.

Using the same definition as in the present study, Van Buren et al. found a prevalence of IDH of $21.3 \%$ after a 6 months assessment of BP measurements during HD treatments. In that observational study, almost every patient experienced at least one episode of IDH, but it occurred in $31.3 \%$ of treatments [9]. The high prevalence found in our study can be mainly explained by the fact that our patients received only 2 dialysis sessions of 4 hours weekly instead of 3 per week as in the majorities of studies. Consequently control of extracellular volume and dry weight is difficult to achieve. Studies have shown that dry weight reduction lowers intradialytic BP [13] [32] [33]. Also in the present study, IDH was considered for a single session while in most reported studies mean SBP over the entire period of follow-up was used to define the prevalence of IDH [4] [7] [8] [9] [10], leading to an underestimation of the frequency IDH, which is intermittent in some patients as demonstrated by Van Buren et al. [9]. Another possible explanation to the high incidence of IDH is that our participants were all from African ancestry, and it is well known that endothelial dysfunction is more frequent in this population and also play a key role in pathogenesis of IDH [34] [35] [36]. Given the known reported adverse outcome of IDH, the finding of this study raised the need of actions to reduce the burden in our setting.

Factors independently associated with increased risk of IDH in this study were male gender, low income, HTN, blood transfusion during the session and use $\geq$ 2 antihypertensive drugs. While the risk was low in older patients, longer duration on dialysis, high dry weight, high UF rate and high BP at the start of the dialysis session. Reported factors that increased the risk of IDH are older age, HTN, low dry weight, higher intradialytic weight gain, lower UF rate, lower SBP at the beginning of the session, short time on HD treatment, high number of antihypertensive medications, low serum creatinine and low albumin [4] [7] [8] [10] [12]. The role of HTN can be due to the modification of the endothelium which occurred with time and also maybe a sign of sympathetic over-activation or greater stimulation of the RAAS [25]. Blood transfusion while bringing new volume is responsible of expansion and then increases BP, while a greater UF rate reduces fluid and then decrease BP. A lower dry weight can be a consequence of a better fluid status preventing fluid overload [13] [25] [35].

We found that older age reduced the risk of IDH while male gender increased the risk. These findings are not reported in the literature and may suggest specific characteristics of our population that need further investigations. The role of specific agents should be determined and all these factors need to be considered in order to reduce the rate of IDH in our setting [23] [24]. One major measure is to reduce dry weight as this is reported to improve IDH over time in some patients [13] [32] [35]. Avoiding dialyzable antihypertensive medications and prefer non dialyzable RAS inhibitors, and administration of ESA subcuta- 
neous can also be considered. Patients should be educated to minimize salt and fluid intake between HD sessions. Also increasing the number of dialysis sessions of our patients could be a major step, hence studies have shown that frequent $\mathrm{HD}$ reduces $\mathrm{BP}$ and the number of prescribed antihypertensive medications [29] [33] [35] [37].

\section{Conclusion}

We found that IDH is very frequent in our setting affecting almost half of the study population. It is more common in male, young patients, those with HTN, low income, who received blood transfusion during sessions, had a short duration on HD, a lower UF and high BP at the beginning of session. Patients were also found to have higher dry weight and many antihypertensive medications. This raises the need of specific measure for the care of affected patients. Further studies are necessary to determine the consequences of IDH in our setting and orientate the treatment of affected patients.

\section{Limitations}

No consensual definition of IDH exists; in the present study we used an increase of $10 \mathrm{mmHg}$ between pre and post dialysis BP for each session. This can lead to overestimation of the phenomenon considering that it is intermittent in some patients, and therefore, it can be less effective to determine the real factors associated with the persistent IDH. It was a single center study, the result can't be generalized. The major strength is that this study describes for the first time the burden of IDH in an SSA setting where HTN is a major cause of CKD and results can help to take action to reduce the burden amongst our patients.

\section{Acknowledgements}

The authors sincerely thank all the patients who participated to this study and the nurses in the HD unit.

\section{Conflicts of Interest}

No relevant conflict of interest.

\section{References}

[1] Agarwal, R., Nissenson, A.R., Batlle, D., Coyne, D.W., Trout, J.R. and Warnock, D.G. (2003) Prevalence, Treatment, and Control of Hypertension in Chronic Hemodialysis Patients in the United States. The American Journal of Medicine, 115, 291-297. https://doi.org/10.1016/S0002-9343(03)00366-8

[2] Health NIo. (2010) United States Renal Data System, USRDS 2010 Annual Data Report: Atlas of Chronic Kidney Disease and End-Stage Renal Disease in the United States. National Institute of Diabetes and Digestive and Kidney Diseases, Bethesda, Maryland, USA.

[3] Flythe, J.E., Inrig, J.K., Shafi, T., Chang, T.I., Cape, K., Dinesh, K., et al. (2013) Association of Intradialytic Blood Pressure Variability with Increased All-Cause and 
Cardiovascular Mortality in Patients Treated with Long-Term Hemodialysis. American Journal of Kidney Diseases. The Official Journal of the National Kidney Foundation, 61, 966-974. https://doi.org/10.1053/j.ajkd.2012.12.023

[4] Inrig, J.K., Patel, U.D., Gillespie, B.S., Hasselblad, V., Himmelfarb, J., Reddan, D., et al. (2007) Relationship between Interdialytic Weight Gain and Blood Pressure among Prevalent Hemodialysis Patients. American Journal of Kidney Diseases. The Official Journal of the National Kidney Foundation, 50, 108-18, 18.e1-4.

[5] Amira, C.O., Braimoh, R.W. and Bello, B.T. (2012) Pattern of Intradialytic Complications at the Lagos University Teaching Hospital. African Journal of Medicine and Medical Sciences, 41, 411-416.

[6] El Harraqui, R., Naima, A., Yassamine, B. and Haddiya, I. (2014) [Management Strategy for Hypertension in Chronic Hemodialysis: A Model Applied to Patient Education (FTE)]. The Pan African Medical Journal, 19, 86.

[7] Inrig, J.K., Oddone, E.Z., Hasselblad, V., Gillespie, B., Patel, U.D., Reddan, D., et al. (2007) Association of Intradialytic Blood Pressure Changes with Hospitalization and Mortality Rates in Prevalent ESRD Patients. Kidney International, 71, 454-461. https://doi.org/10.1038/sj.ki.5002077

[8] Losito, A., Del Vecchio, L., Del Rosso, G. and Locatelli, F. (2016) Postdialysis Hypertension: Associated Factors, Patient Profiles, and Cardiovascular Mortality. American Journal of Hypertension, 29, 684-689. https://doi.org/10.1093/ajh/hpv162

[9] Van Buren, P.N., Kim, C., Toto, R.D. and Inrig, J.K. (2012) The Prevalence of Persistent Intradialytic Hypertension in a Hemodialysis Population with Extended Follow-Up. The International Journal of Artificial Organs, 35, 1031-1038. https://doi.org/10.1177/039139881203501201

[10] Yang, C.Y., Yang, W.C. and Lin, Y.P. (2012) Postdialysis Blood Pressure Rise Predicts Long-Term Outcomes in Chronic Hemodialysis Patients: A Four-Year Prospective Observational Cohort Study. BMC Nephrology, 13, 12. https://doi.org/10.1186/1471-2369-13-12

[11] Foley, R.N., Parfrey, P.S., Harnett, J.D., Kent, G.M., Murray, D.C. and Barre, P.E. (1996) Impact of Hypertension on Cardiomyopathy, Morbidity and Mortality in End-Stage Renal Disease. Kidney International, 49, 1379-1385.

https://doi.org/10.1038/ki.1996.194

[12] Inrig, J.K., Patel, U.D., Toto, R.D. and Szczech, L.A. (2009) Association of Blood Pressure Increases during Hemodialysis with 2-Year Mortality in Incident Hemodialysis Patients: A Secondary Analysis of the Dialysis Morbidity and Mortality Wave 2 Study. American Journal of Kidney Diseases, 54, 881-890. https://doi.org/10.1053/j.ajkd.2009.05.012

[13] Agarwal, R. and Light, R.P. (2010) Intradialytic Hypertension Is a Marker of Volume Excess. Nephrology Dialysis Transplantation, 25, 3355-3361. https://doi.org/10.1093/ndt/gfq210

[14] Gũnal, A., Karaca, I., Celiker, H., Ilkay, E. and Duman, S. (2001) Paradoxical Rise in Blood Pressure during Ultrafiltration Is Caused by Increased Cardiac Output. Journal of Nephrology, 15, 42-47.

[15] Nishimura, M., Tokoro, T., Nishida, M., Hashimoto, T., Kobayashi, H., Yamazaki, S., et al. (2010) Sympathetic Overactivity and Sudden Cardiac Death among Hemodialysis Patients with Left Ventricular Hypertrophy. International Journal of Cardiology, 142, 80-86. https://doi.org/10.1016/j.ijcard.2008.12.104

[16] Rubinger, D., Backenroth, R. and Sapoznikov, D. (2012) Sympathetic Activation and Baroreflex Function during Intradialytic Hypertensive Episodes. PLoS ONE, 7, 
e36943. https://doi.org/10.1371/journal.pone.0036943

[17] Inrig, J.K., Van Buren, P., Kim, C., Vongpatanasin, W., Povsic, T.J. and Toto, R. (2012) Probing the Mechanisms of Intradialytic Hypertension: A Pilot Study Targeting Endothelial Cell Dysfunction. Clinical Journal of the American Society of Nephrology, 7, 1300-1309. https://doi.org/10.2215/CJN.10010911

[18] Inrig, J.K., Van Buren, P., Kim, C., Vongpatanasin, W., Povsic, T.J. and Toto, R.D. (2011) Intradialytic Hypertension and Its Association with Endothelial Cell Dysfunction. Clinical Journal of the American Society of Nephrology, 6, 2016-2024. https://doi.org/10.2215/CJN.11351210

[19] Kyriazis, J., Katsipi, I., Stylianou, K., Jenakis, N., Karida, A. and Daphnis, E. (2007) Arterial Stiffness Alterations during Hemodialysis: The Role of Dialysate Calcium. Nephron Clinical Practice, 106, c34-c42. https://doi.org/10.1159/000101482

[20] Locatelli, F., Covic, A., Chazot, C., Leunissen, K., Luño, J. and Yaqoob, M. (2004) Optimal Composition of the Dialysate, with Emphasis on Its Influence on Blood Pressure. Nephrology Dialysis Transplantation, 19, 785-796. https://doi.org/10.1093/ndt/gfh102

[21] Penne, E.L., Levin, N.W. and Kotanko, P. (2010) Improving Volume Status by Comprehensive Dietary and Dialytic Sodium Management in Chronic Hemodialysis Patients. Blood Purification, 30, 71-78. https://doi.org/10.1159/000317124

[22] Chou, K.-J., Lee, P.-T., Chen, C.-L., Chiou, C.-W., Hsu, C.-Y., Chung, H.-M., et al. (2006) Physiological Changes during Hemodialysis in Patients with Intradialysis Hypertension. Kidney International, 69, 1833-1838.

https://doi.org/10.1038/sj.ki.5000266

[23] Abraham, P. and Macres, M. (1991) Blood Pressure in Hemodialysis Patients during Amelioration of Anemia with Erythropoietin. Journal of the American Society of Nephrology, 2, 927-936.

[24] Buckner, F.S., Eschbach, J.W., Haley, N.R., Davidson, R.C. and Adamson, J.W. (1990) Hypertension Following Erythropoietin Therapy in Anemic Hemodialysis Patients. American Journal of Hypertension, 3, 947-955. https://doi.org/10.1093/ajh/3.12.947

[25] Inrig, J.K. (2010) Intradialytic Hypertension: A Less-Recognized Cardiovascular Complication of Hemodialysis. American Journal of Kidney Diseases, 55, 580-589. https://doi.org/10.1053/j.ajkd.2009.08.013

[26] Halle, M.P., Kengne, A.P. and Ashuntantang, G. (2009) Referral of Patients with Kidney Impairment for Specialist Care in a Developing Country of Sub-Saharan Africa. Renal Failure, 31, 341-348. https://doi.org/10.1080/08860220902882014

[27] Kaze, F.F., Ashuntantang, G., Kengne, A.P., Hassan, A., Halle, M.P. and Muna, W. (2012) Acute Hemodialysis Complications in End-Stage Renal Disease Patients: The Burden and Implications for the Under-Resourced Sub-Saharan African Health Systems. Hemodialysis International, 16, 526-531. https://doi.org/10.1111/j.1542-4758.2012.00692.x

[28] Lengani, A., Laville, M., Serme, D., Fauvel, J., Ouandaogo, B. and Zech, P. (1993) Renal Insufficiency in Arterial Hypertension in Black Africa. Presse Medicale, 23, 788-792.

[29] Osafo, C., Mate-Kole, M., Affram, K. and Adu, D. (2011) Prevalence of Chronic Kidney Disease in Hypertensive Patients in Ghana. Renal Failure, 33, 388-392. https://doi.org/10.3109/0886022X.2011.565140

[30] Halle, M.P., Takongue, C., Kengne, A.P., Kaze, F.F. and Ngu, K.B. (2015) Epidemi- 
ological Profile of Patients with End Stage Renal Disease in a Referral Hospital in Cameroon. BMC Nephrology, 16, 59. https://doi.org/10.1186/s12882-015-0044-2

[31] Okin, P.M., Wright, J.T., Nieminen, M.S., Jern, S., Taylor, A.L., Phillips, R., et al. (2002) Ethnic Differences in Electrocardiographic Criteria for Left Ventricular Hypertrophy: The Life Study. Losartan Intervention for Endpoint. American Journal of Hypertension, 15, 663-671. https://doi.org/10.1016/S0895-7061(02)02945-X

[32] Agarwal, R., Alborzi, P., Satyan, S. and Light, R.P. (2009) Dry-Weight Reduction in Hypertensive Hemodialysis Patients DRIP, a Randomized, Controlled Trial. Hypertension, 53, 500-507. https://doi.org/10.1161/HYPERTENSIONAHA.108.125674

[33] Fourtounas, C. (2010) "Malignant" Intradialytic Hypertension: A Severe Form of Intradialytic Hypertension. American Journal of Kidney Diseases. The Official Journal of the National Kidney Foundation, 56, 418.

[34] Duck, M.M. and Hoffman, R.P. (2007) Impaired Endothelial Function in Healthy African-American Adolescents Compared to Caucasians. The Journal of Pediatrics, 150, 400-406. https://doi.org/10.1016/j.jpeds.2006.12.034

[35] Van Buren, P.N. and Inrig, J.K. (2016) Mechanisms and Treatment of Intradialytic Hypertension. Blood Purification, 41, 188-193. https://doi.org/10.1159/000441313

[36] Wei, P., Milbauer, L., Enenstein, J., Nguyen, J., Pan, W. and Hebbel, R. (2011) Differential Endothelial Cell Gene Expression by African Americans versus Caucasian Americans: A Possible Contribution to Health Disparity in Vascular Disease and Cancer. BMC Medicine, 9, 2. https://doi.org/10.1186/1741-7015-9-2

[37] Cappuccio, F.P., Micah, F.B., Emmett, L., Kerry, S.M., Antwi, S., Martin-Peprah, R., et al. (2004) Prevalence, Detection, Management, and Control of Hypertension in Ashanti, West Africa. Hypertension, 43, 1017-1022.

https://doi.org/10.1161/01.HYP.0000126176.03319.d8 